\title{
Imaging of Murine Brain Tumors Using a 1.5 Tesla Clinical MRI System
}

\author{
Wouter R. van Furth, Suzanne Laughlin, Michael D. Taylor, Bodour Salhia, Todd \\ Mainprize, Mark Henkelman, Michael D. Cusimano, Cameron Ackerley, James T. Rutka
}

\begin{abstract}
Background: In this study, we investigated the feasibility of using a 1.5 Tesla (T) clinical magnetic resonance imaging (MRI) system for in vivo assessment of three histopathologically different brain tumor models in mice. Methods: We selected mouse models in which tumor growth was observed in different intracranial compartments: Patched ${ }^{+/}$heterozygous knock-out mice for tumor growth in the cerebellum $(\mathrm{n}=5)$; U87 MG human astrocytoma cells xenografted to the frontal lobe of athymic mice $(\mathrm{n}=15)$; and F5 ( $\mathrm{n}=15)$ or IOMMLee $(n=15)$ human malignant meningioma cells xenotransplanted to the athymic mouse skull base or convexity. Mice were imaged using a small receiver surface coil and a clinical 1.5 T MRI system. T1- and fast spin echo T2-weighted image sequences were obtained in all animals. Gadolinium was injected via tail vein to better delineate the intracranial tumors. Twenty mice were followed by serial MRI to study tumor growth over time. In these mice, images were typically performed after tumor implantation, and at two week intervals. Mice were euthanized following their last imaging procedure, and their tumors were examined by histopathology. The histopathological preparations were then compared to the last MR images to correlate the imaging features with the pathology. Results: Magnetic resonance imaging delineated the tumors in the cerebellum, frontal lobes and skull base in all mouse models. The detection of intracranial tumors was enhanced with prior administration of gadolinium, and the limit of resolution of brain tumors in the mice was 1-2 $\mathrm{mm}^{3}$. Sequential images performed at different time intervals showed progressive tumor growth in all animals. The MR images of tumor size and location correlated accurately with the results of the histopathological analysis. Conclusion: Magnetic resonance imaging of murine brain tumors in different intracranial compartments is feasible with a $1.5 \mathrm{~T}$ clinical MR system and a specially designed surface coil. Tumors as small as $1-2 \mathrm{~mm}^{3}$ can be detected with good image resolution. Mice harbouring nascent brain tumors can be followed sequentially by serial MR imaging. This may allow for a noninvasive means by which tumor growth can be measured, and novel therapies tested without resorting to sacrifice of the mice.
\end{abstract}

RÉSUMÉ: Imagerie au moyen d'un système d'IRM 1.5 Tesla utilisé en clinique de tumeurs murines produites par génie génétique et xénotransplantées. Introduction: Nous avons évalué la possibilité d'utiliser un système d'imagerie par résonance magnétique (IRM) 1.5 Tesla (T) utilisé en clinique pour l'étude in vivo de trois modèles différents au point de vue histopathologique de tumeurs cérébrales chez la souris. Méthodes: Nous avons choisi des modèles présentant une tumeur dans différents compartiments intracrâniens: des souris knock-out hétérozygotes Patched+/- pour les tumeurs du cervelet $(\mathrm{n}=5)$; des cellules d'astrocytome humain U87 MG xénotransplantées dans le lobe frontal de souris athymiques $(\mathrm{n}=15)$; et des cellules de méningiome malin humain F5 $(n=15)$ ou IOMM Lee $(n=15)$ xénotransplantées à la base du crâne ou à la convexité de souris athymiques. Une petite sonde de surface et un système IRM 1.5 T utilisé en clinique ont été utilisés et on a obtenu des séquences pondérées T1 et écho de spin T2 chez tous les animaux. Du gadolinium a été injecté par la veine de la queue pour mieux faire ressortir les tumeurs intracrâniennes. Vingt souris ont été suivies par IRM sérié pour suivre la croissance tumorale. Chez ces souris, les images ont été obtenues après l'implantation de la tumeur et aux deux semaines par la suite. Les souris ont été sacrifiées après la dernière séance d'imagerie et les tumeurs ont été examinées en histopathologie. Les préparations histopathologiques ont ensuite été comparées aux dernières images obtenues par RM pour établir des corrélations entre l'imagerie et la pathologie. Résultats: L'IRM a mis en évidence les tumeurs dans le cervelet, les lobes frontaux et à la base du crâne chez tous les modèles de souris. La détection des tumeurs intracrâniennes était rehaussée par l'administration préalable de gadolinium et la limite de résolution des tumeurs cérébrales chez les souris était de 1-2 $\mathrm{mm}^{3}$. Des images séquentielles obtenues à différents intervalles ont montré une croissance progressive de la tumeur chez tous les animaux. Les images de la taille et de la localisation de la tumeur obtenues par RM correspondaient exactement aux résultats de l'analyse histopathologique. Conclusion: Il est possible d'utiliser un système de RM $1.5 \mathrm{~T}$ utilisé en clinique et une sonde spécialement conçue pour l'IRM de tumeurs cérébrales dans différents compartiments intracrâniens chez la souris. Avec une bonne résolution, on peut détecter des tumeurs de 1 ou $2 \mathrm{~mm} 3$. On peut suivre des souris porteuses de tumeurs cérébrales naissantes par l'IRM en série. Cette méthode permet de suivre la croissance tumorale de façon non effractive et de tester de nouveaux traitements sans devoir sacrifier les souris.

Can. J. Neurol. Sci. 2003; 30: 326-332

In vivo assessment of tumor growth in animal models is becoming an important method of measuring tumor growth rate. As new models of brain tumors are being developed in mice using various transgenic and knock-out strategies which more accurately recapitulate the human disease, ${ }^{1-3}$ it is essential that non-invasive methods, such as magnetic resonance imaging (MRI) of these models, be developed and made accessible so that tumor response to therapy can be determined.
From the Department of Diagnostic Imaging, Hospital for Sick Children, University of Toronto, Department of Medical Imaging, (SL); Department of Medical Biophysics, University of Toronto, (MH); and Division of Neurosurgery, St. Michael's Hospital, University of Toronto, (MDC); Arthur \& Sonia Labatt Brain Tumour Research Centre, Hospital for Sick Children (WRvF, MDT, BS, TM, CA, JTR); Toronto, Ontario, Canada. ReCeIVED JanuARY 15, 2003. ACCEPTED IN FINAL FORM JUNe 11, 2003.

Reprint requests to: James T. Rutka, Arthur \& Sonia Labatt Brain Tumour Research Centre, The Hospital for Sick Children, Elizabeth McMaster Building, Room 3005, 555 University Avenue, Toronto, Ontario, Canada M5G 1X8. E-mail: james.rutka@ sickkids.ca 
Magnetic resonance imaging of intracranial tumor growth has been demonstrated in tumor models using rats ${ }^{4-17}$ and mice..$^{2,18-24}$ Most investigators have used a dedicated rodent MRI with a strong magnetic field (often 7-9 Tesla (T) $)^{22}$ and a small bore. ${ }^{21,25}$ Although the quality of the imaging on a dedicated murine 7-9 T MRI is superior to lower magnetic field MR images, relatively few centers are presently equipped with such a facility. A $1.5 \mathrm{~T}$ MRI system has previously been used to image rat brain, ${ }^{14,17}$ rat gliomas ${ }^{22,26,27}$ and murine gliomas. ${ }^{23}$ As brain tumor research in the future will rely heavily on newly developed mouse models, here we have investigated the possibility of imaging brain tumors that arise in different intracranial compartments in a variety of orthotopic mouse models using a widely available clinical 1.5 T MRI system.

\section{MATERIALS AND METHODS}

\section{Animal care protocol}

Athymic mice (Swiss nu/nu) and Patched $^{+/-}$heterozygotes were used to study brain tumor growth in various intracranial compartments. All mice described in the study were housed in the animal care facility at the Hospital for Sick Children (HSC). Approval to use the mice in this study was granted by the Animal Care Committee, HSC. The Institutional Hygiene Committee at HSC approved the use of the clinical MRI system for imaging of experimental animals. Housing, surgery and transport of mice were performed according to local standardized procedures. The mice were housed five per cage with water and food ad libitum. Mice harbouring intracranial tumors were observed daily for dehydration or signs of tumor growth including rumpled fur, decreased feeding, accentuation of the thoracic kyphosis, paralysis, ataxia and domed heads. Some mice were imaged immediately after symptoms were documented and then sacrificed within hours for pathological correlation. Others were serially imaged, with initial imaging being performed prior to onset of symptoms or signs of increased intracranial pressure.

\section{Brain tumor cell lines}

U87 MG malignant glioma (from ATCC), IOMM-Lee ${ }^{28}$ and F5 malignant meningioma ${ }^{29}$ (gift from Dr. S. D. Rabkin, Department of Neurosurgery, Georgetown University Medical Center, Washington) cell lines were cultured in Dulbecco's modified eagle's medium with low glucose, supplemented with $10 \%$ fetal calf serum, penicillin and streptomycin and incubated at $37^{\circ} \mathrm{C}$ in a humidified atmosphere of $95 \%$ air and $5 \%$ carbon dioxide. The cells were trypsinized, washed in sterile PBS, centrifuged and resuspended in a volume of sterile phosphate buffered saline (PBS) resulting in $2 \times 10^{5}$ cells $/ \mu \mathrm{L}$.

\section{Anesthesia}

For surgery or MRI, mice were anesthetized with a combination of Hypnorm (composition: 0.315 mg fentanyl citrate $/ \mathrm{ml}, 10 \mathrm{mg}$ fluanisone/ml, Janssen Pharmaceutica, Beerse, Belgium) and Midazolam (5 mg/ml, Roche, Mississauga, Canada) injected intraperitoneally (diluted in distilled water Hypnorm 1:4, Midazolam 1:6.6, mixed in equal volume, $0.1 \mathrm{cc}$ per 10 gram). Due to the total length of time required to image a group of mice, it was frequently necessary to administer a second dose of anesthetic. The mice were not intubated. After anesthesia, mice received a subcutaneous injection of $0.5 \mathrm{ml}$ saline to replenish fluids and were kept warm until recovery.

\section{Intracranial injection}

Female athymic nude mice (Swiss nu/nu) six to eight weeks old were used for xenotransplantation studies. After induction of anesthesia, mice were fixed in a rodent stereotactic head holder (ASI instruments, Warren, MI). Aseptic surgical technique was strictly followed. ${ }^{30}$ The head was prepped with Betadine. Lidocaine (Abbott Laboratories, Abbott Park, IL) was subperiostially injected at the vertex of the cranium. After a linear midline skin incision, a burr hole was made $3 \mathrm{~mm}$ anterior and $2 \mathrm{~mm}$ lateral to the bregma (Dremel drill, Racine, WI, USA). Cells were injected with a Hamilton microsyringe $(7105 \mathrm{KH}$, Hamilton Company, Reno, NV) attached to the stereotactic holder. Tumor cells were injected intracerebrally at a depth of 3 $\mathrm{mm}$ beneath the cortical surface (U87 MG, $\mathrm{n}=15$ mice) or at the skull-base (IOMM-Lee, $\mathrm{n}=15$ mice; and F5, $\mathrm{n}=15$ mice)at a depth of approximately $7 \mathrm{~mm}$, when bony resistance was encountered. Each mouse was injected with $1 \times 10^{6}$ cells in a volume of $5 \mu \mathrm{L}$ over a period of 60 seconds. After one minute the needle was slowly removed. The skin was closed with interrupted Dexon 5.0 sutures.

\section{Patched $^{+/-}$heterozygote mice}

A colony of Patched $^{+/-}$mice were a gift of Dr. C.C. Hui (Department of Developmental Biology, Hospital for Sick Children). Mice were genotyped by polymerase chain reaction using DNA from tail clippings. Primers used were

P1, 5'-GACCATGTCTGCAACACTTAGGTTCC-3';

P2, 5'-GAAGGCCAGGAGGAGAAGGCTCAC-3';

P3, 5'-CTGTGCTCGACGTTGTCACTG-3';

P4, 5'-GATCCCCTCAGAAGAACTCGT-3', 31

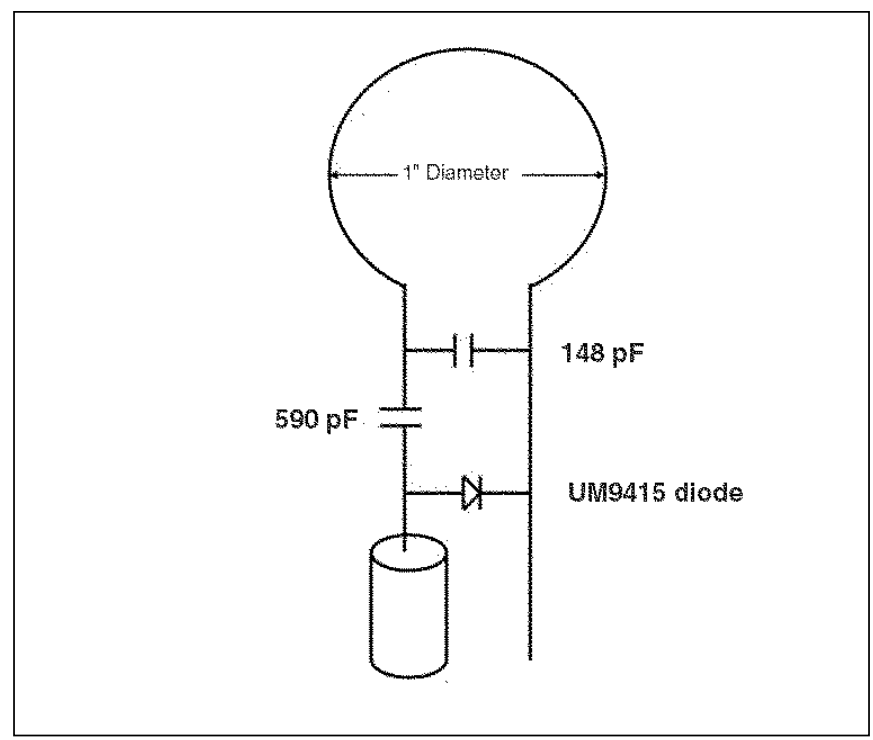

Figure 1: Surface coil schematic. The suface coil is a single loop 1-inch diameter copper wire without breaks tuned to $63.8 \mathrm{MHz}$ with an impedance of 65 ohms at 0 degrees phase when loaded. It has a diode protection circuit activated by the signal to deactivate the coil during transmit time (Microsemi Corps, Watertow, MA). There are two capacitors (590 and 148 pF, Dielectric Laboratories Inc., Cazenovia, $N Y)$ within the circuit. 
Polymerase chain reaction products were analyzed by agarose gel electrophoresis and visualization on an UV light box. Five Patched $^{+/-}$mice (three symptomatic, two asymptomatic) were selected for imaging as described below.

\section{Magnetic resonance imaging}

A 1.5 T clinical MRI scanner (CVMR, LX platform, 8.2.5 software, GE Medical Systems, Milwaukee) was used to image brain tumors in both symptomatic and asymptomatic mice. Initial studies were performed with a wrist extremity coil or 3 inch phased array coils. A specially designed small surface receiver coil was used in subsequent studies to improve the signal to noise ratio. This coil was designed and donated by Dr. M. Henkelman (Department of Medical Biophysics, University of Toronto) (Figure 1). Gadolinium was administered intravenously via tail vein injections $(0.2 \mathrm{ml} / \mathrm{kg}, 1: 20$ dilution of gadolinium). Scanning was performed immediately after intravenous injection of the contrast agent.

High resolution fast spin echo T2-weighted imaging (TR 4000, TE 82, FOV $5 \times 3.75 \mathrm{~cm}$, matrix 512 x 384, 3NEX using a $1.5 \mathrm{~mm}$ slice thickness with a $0.2 \mathrm{~mm}$ gap and an acquisition time of $7 \mathrm{~min} 28 \mathrm{sec}$ ) was performed in multiple planes as well as conventional T1-weighted spin echo sequences prior to and following the administration of gadolinium (TR 500, TE 11, FOV 5 x 3.75, matrix 256 x 160, 2 NEX again with a $1.5 \mathrm{~mm}$ slice thickness with a $0.2 \mathrm{~mm}$ gap resulting in an acquisition time of $2 \mathrm{~min} 4 \mathrm{sec}$ ).

\section{Histological analysis}

Deeply anesthetized mice were euthanized and then perfused with a buffered formalin solution. The brain was quickly removed under a dissecting microscope, sectioned coronally and embedded in paraffin. Paraffin sections ( $5 \mu$ thick) were stained with hematoxylin and eosin and examined by light microscopy. The orientation, and size of the brain tumors with respect to the surrounding normal brain on the histological sections were then correlated with the images obtained by MR.

\section{RESUltS}

\section{Feasibility}

Noninvasive, serial assessments of intracranial tumors in mice with a clinical 1.5 T MRI system were feasible and safe. There were no mortalities relating to either the anesthetic used or imaging procedure performed. After introduction of the small surface receiver coil, a significant improvement in image quality was noted primarily due to improved signal to noise ratio (Figure $2 \mathrm{~A}, \mathrm{~B}$ ) when compared with the wrist extremity coil (Figure 2C). The spatial resolution was excellent and structures of 1-2 mm, such as the fourth ventricle, were easily identified. And tumors as small as 1-2 $\mathrm{mm}^{3}$ could be appreciated on the images.

\section{Intracerebral glioma model}

Intracerebral tumors formed in all mice implanted with U87 MG glioma cells. Serial imaging of the implanted tumor was performed in five tumor bearing mice. As one representative example of this group, 19 days after intracerebral injection of U87 MG glioma cells, a small homogeneously enhancing intracranial mass was noted (Figure 2A). On day 33 post implantation, the mouse was found to be symptomatic with signs of raised intracranial pressure. Imaging studies revealed a significant interval increase in the size of the tumor. After intravenous injection of gadolinium, a well-defined heterogeneously enhancing mass was visualized with evidence of extracranial extension through the calvarium likely along the needle tract (Figure 2B). There was significant mass effect noted with midline shift to the left and obstructive hydrocephalus with moderate dilatation of the lateral ventricles. The central hypoattenuation suggested cystic changes within the tumor or central necrosis. Histological examination of the tumors revealed the absence of any vasculature in the central portions without necrosis (Figure 2D). The periphery of the tumors had a wellestablished blood supply (Figure 2E) which would explain the observed enhancement pattern.

\section{Skull base meningioma model}

Intracerebral injection of IOMM-Lee or F5 malignant meningioma cells resulted in spherical tumors that grew preferentially in the subdural space. On T1-weighted images after gadolinium injection these tumors typically showed mild enhancement with clearly defined tumor edges (data not shown). The meningiomas that resulted from injection of F5 meningioma cells showed a growth pattern similar to human convexity meningiomas. A tumor could be depicted in asymptomatic mice injected with F5 meningioma cells as early as 21 days after injection, with subsequent images revealing tumor growth (data not shown). T1-weighted images in mice with symptoms of raised intracranial pressure 29 days after injection of F5 meningioma cells, showed large, spherical tumors with bright homogeneous enhancement (Figure 3A). The tumors had extracranial growth through the burr hole. There was mass effect causing midline shift and mild hydrocephalus. The tentorium showed moderate enhancement. The tumor margins were sharp, with no evidence for brain or bone invasion. On the histological sections of the brain, atypical meningiomas were seen growing in the subdural space (Figure 3B). Histological examination revealed the tumor growing along the injection tract into the subdural space and, in some mice, extradurally through the burr hole. By histopathology, the tumors had a lobulated pattern. Typical whorls were not observed and necrosis was absent.

Mice with IOMM-Lee meningioma cells injected at the skull base developed tumors highly similar to human skull base meningiomas. The meningioma encased the cranial nerves, grew along the optic nerve and invaded bone of the skull base. T1weighted images of symptomatic mice 14 days after injection showed a hypointense subdural mass that compressed the brain and caused midline shift. After gadolinium administration, enhancement of the tumor margins was seen (Figure 3C). Destruction of the skull base with tumor invasion was shown on the axial MRI. The histology showed a highly cellular tumor that invaded the skull base (Figure 3D). Invasion of the mouse brain was present, but was considerably less than the amount of bone invasion as determined by histopathology. The MIB-1 index was $30 \%$. Five mice injected with IOMM-Lee cells demonstrated widespread dissemination of tumor in the subarachnoid space recapitulating meningeal carcinomatosis (data not shown).

\section{Cerebellar medulloblastoma model}

Patched $^{+/-}$mice were observed to develop cerebellar tumors with a striking histological resemblance to human medullo- 

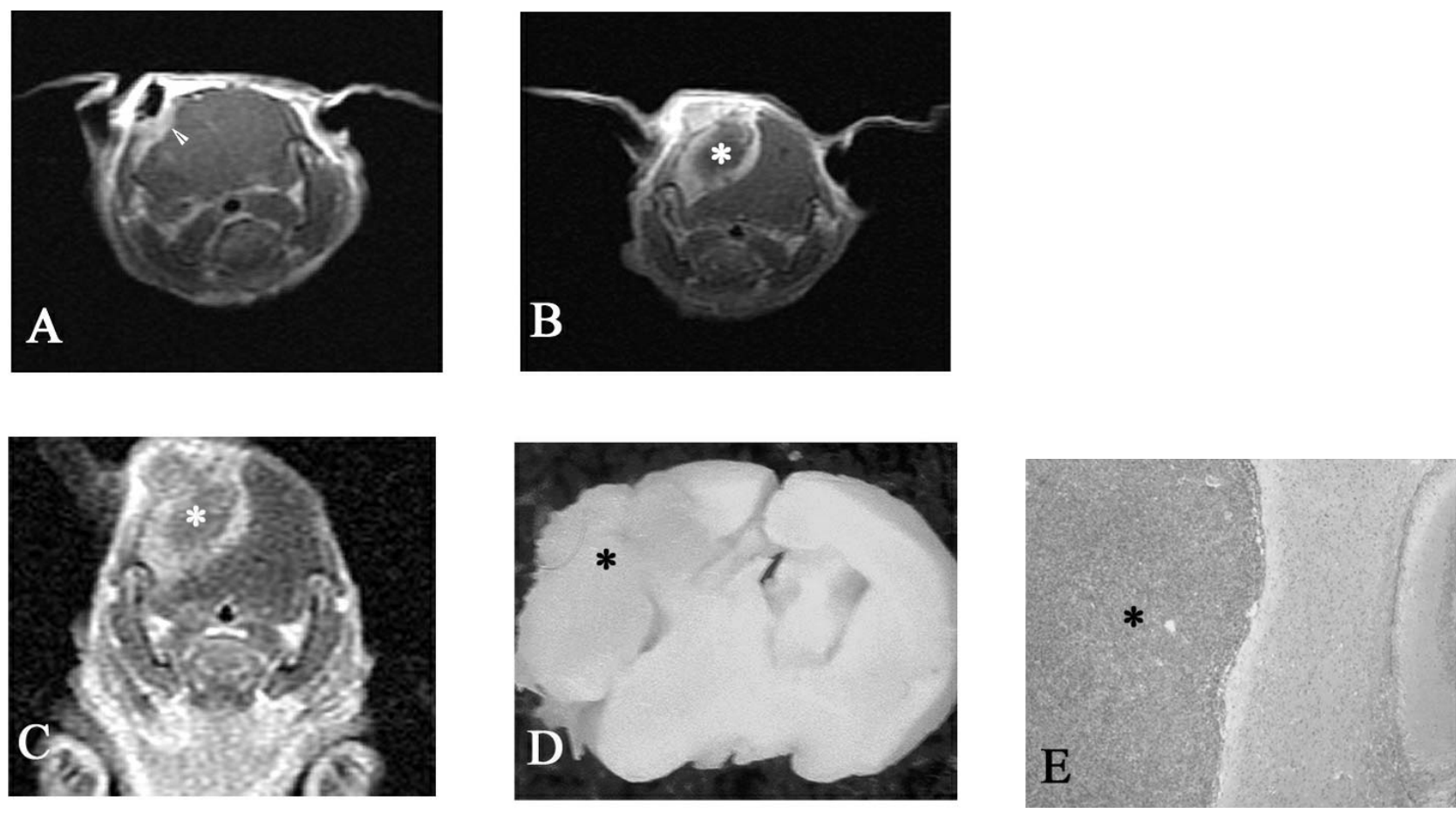

Figure 2: Glioma model. MRI and pathology of brain tumor after intracranial injection of U87 astrocytoma cells.

A) Asymptomatic mouse 19 days post injection. Coronal MRI shows a small enhancing en-plaque mass deep to the calvarium, appearing extra-axial on the gadolinium enhanced T1-weighted image. There is some soft tissue swelling of the overlying scalp related to the previous surgery. This mouse is clinically asymptomatic.

B) Same mouse as in A), now symptomatic at 33 days post-injection. Interval growth of the mass is noted causing midline shift and obstructive hydrocephalus. The ventricles are somewhat enlarged. Images from A) and B) were obtained using a small surface receiver coil.

C) Imaging of same mouse as in B) using wrist coil. While the tumor is still visualized, the quality and resolution of the image is not as good as with the surface receiver coil.

D) Gross specimen of mouse brain with tumor showing tumor size and adjacent brain edema. Hematoxylin and eosin stain of mouse tumor showing the demarcation zone between the tumor and mouse brain. The tumor border is well-vascularized whereas the central portion of the tumor is relatively devoid of blood vessels. Arrowhead pointing to tumor. Asterisk (*) indicates tumor. Magnification, $x 25$.

Figure 3: Meningioma models.

A) Coronal MRI of mouse brain tumor 29 days after implantation of F5 meningioma cells. A large, spherical tumor with relatively homogeneous, intense enhancement on the T1-weighted image is seen, causing midline shift and hydrocephalus. The tumor has extracranial extension.

$B)$ Histopathology of mouse meningioma from A) after imaging on day 29. Meningioma cells form a tumor that has grown along the injection tract into the subdural space. Extracranial extension is seen. Brain invasion is not present. $H \& E, x 25$.

C) Coronal MRI of mouse brain tumor 14 days after implantation of IOMM-Lee malignant meningioma cells. A hypointense extra-axial mass growing at the skull base demonstrating moderate enhancement of the tumor edges is noted on the T1-weighted image. The skull base on the side of the tumor is destroyed by tumor invasion. Tumor growth is also seen in the parapharyngeal area.

D) Histopathology of mouse brain tumor shown in C) after completion of imaging. IOMM-Lee cells form a tumor with invasion of bone as depicted on the MR. Invasion of the mouse brain is limited to growth along the blood vessels. The tumor is poorly vascularized. Asterisk (*) indicates tumor. $H \& E, x 25$.
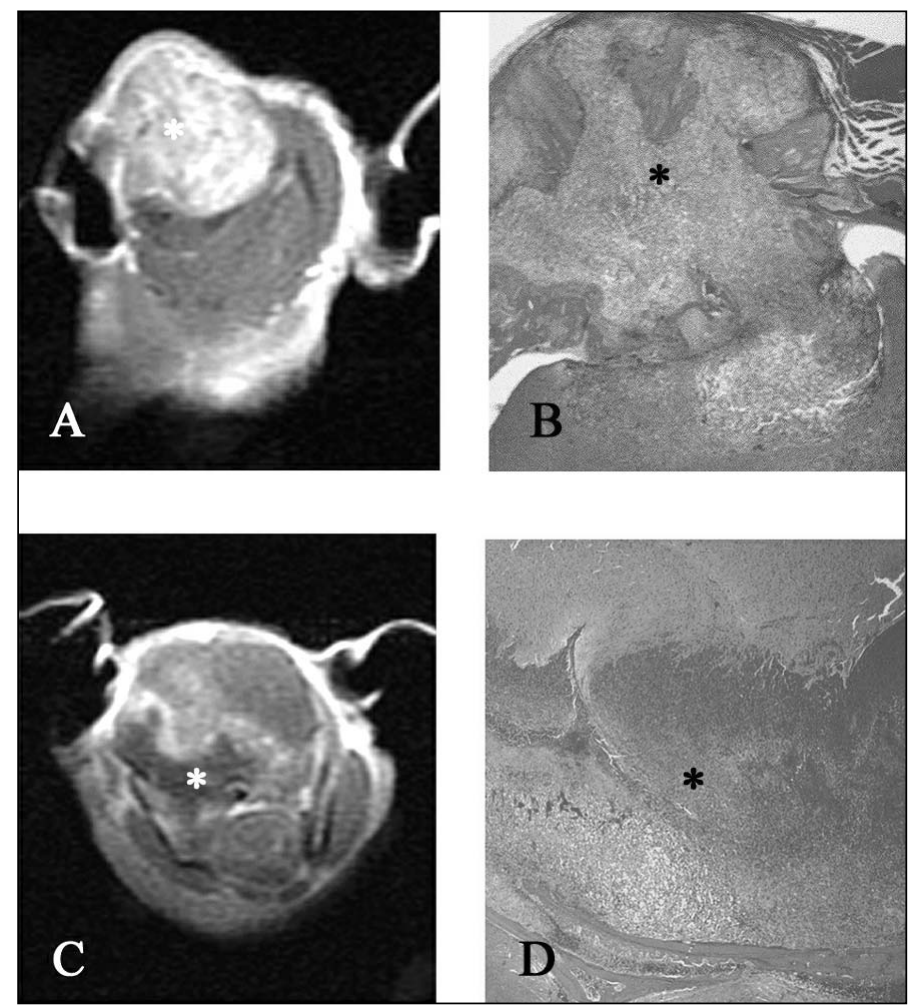

Volume 30, No. 4 - November 2003 


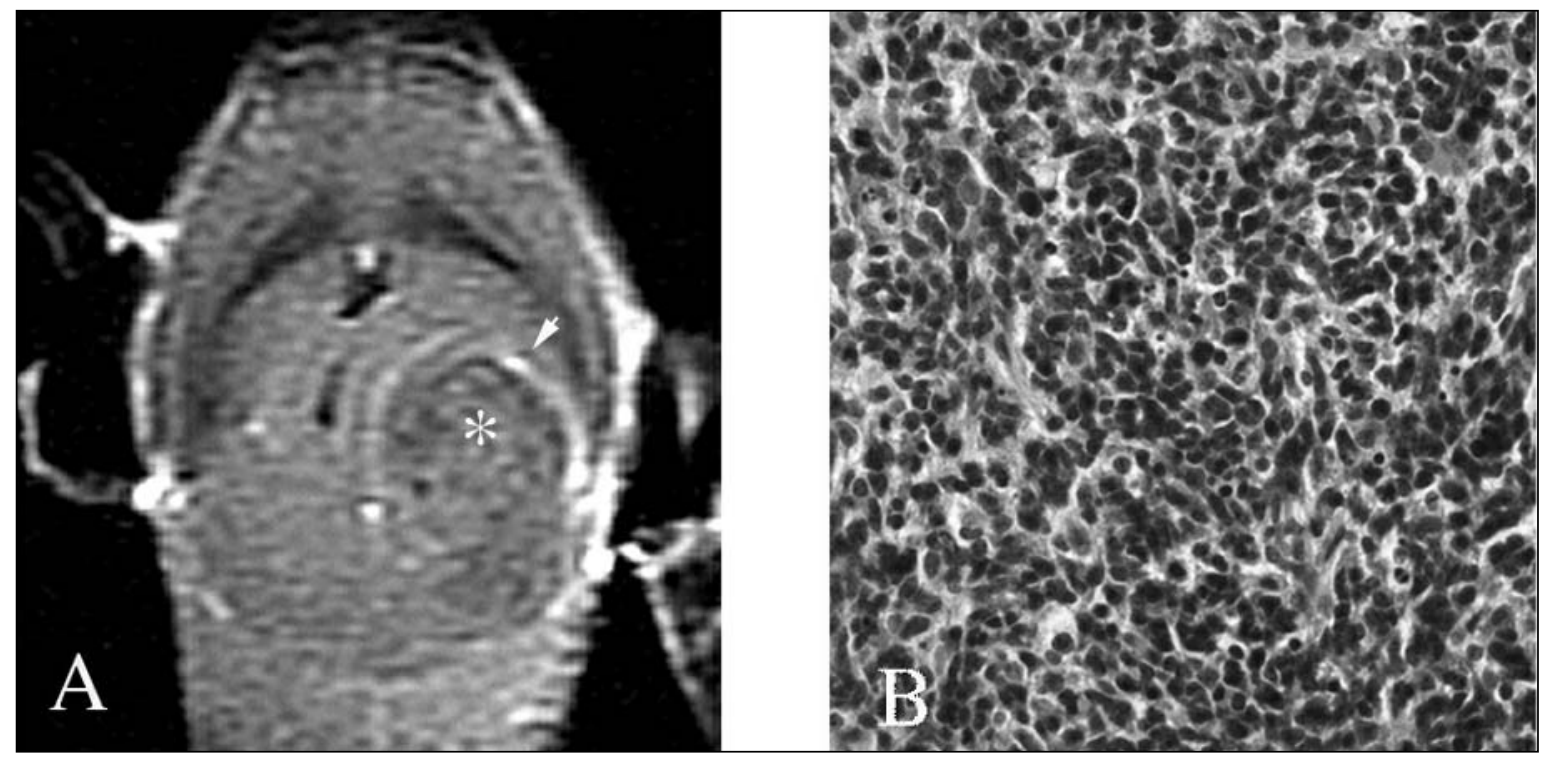

Figure 4: Medulloblastoma model in Patched $^{+/-}$mice

A) A sharply demarcated heterogeneous mass with hypointense and isointense components on axial T1-weighted images is noted with rim enhancement after intravenous gadolinium injection. Obstructive hydrocephalus with moderate dilatation of the lateral, third and fourth ventricles is noted as well as midline shift and compression of the left lateral aspect of the cerebellum.

B) Histopathology of brain tumor from mouse in A) shows a small blue cell tumor. The tumor cells show variability in nuclear and cytoplasmic size and shape. $H \& E, x 25$. Asterisk (*) indicates tumor. Arrowhead points at rim enhancement.

blastoma. T2-weighted MRIs of symptomatic Patched $^{+/-}$mice showed hyperdense cerebellar mass. On T1-weighted imaging following intravenous gadolinium injection, the tumor was predominantly hypointense with rim enhancement (Figure 4A). The histological analysis of the brain showed a highly cellular tumor, with dense small blue tumor cells (Figure 4B). These cells were heterogeneous in size with significant nucleolar variation. No necrosis or rosette formation was present.

\section{Discussion}

In this study, we have shown that a $1.5 \mathrm{~T}$ clinical MR system is capable of imaging brain tumors that arise in different intracranial compartments of the mouse brain. Administration of gadolinium prior to imaging enhances the detection of the tumors. Tumors as small as $1-2 \mathrm{~mm}^{3}$ in size can be identified using this technique. We have also shown that mice harbouring brain tumors can be followed with serial MRIs, and that the growth and size of these tumors can be monitored noninvasively. Finally, we have demonstrated that the tumours that are visualized on MR correlate accurately with the histopathology of these lesions and their relationship to surrounding tissues such as normal brain or skull.

In the past, translational research utilized human tumor explants that grow poorly in the intracranial space or cell lines whose geno/phenotypic fidelity to the original tumor remains questionable. In the future, the development of novel therapeutic strategies for brain tumors may arise from studying genetically engineered animal models that faithfully mimic the human condition. ${ }^{2}$ For these reasons, we tested the feasibility of using a clinical 1.5 T MRI to obtain fast, high quality images of tumors growing in three separate intracranial compartments in mice. We originally tried two different receiver coils, a wrist extremity coil and a temporomandibular joint coil. The resolution that we obtained was much superior with the specially designed $2.5 \mathrm{~cm}$ solenoidal coil. Although the first two receivers are adequate in detecting larger tumors in symptomatic mice, the $2.5 \mathrm{~cm}$ solenoidal coil improved spatial resolution such that tumors as small as $1-2 \mathrm{~mm}^{3}$ could be visualized in asymptomatic mice.

Most imaging studies to date examining the murine brain involve dedicated research magnets that are smaller and more powerful than clinical MRI units. There have been many previous studies in which such MRI units were used to study orthotopic rodent gliomas, but these have been performed using xenografts of rat glioma cell lines such as $\mathrm{C6}^{26}$ or 9L. $6,9,12,15,25$ Recently, studies have emerged in which MRI of murine brain tumors has been performed with 1.5 - 7 T magnet strength., 21-24 At higher magnet strength such as $7 \mathrm{~T}$, the images that have been rendered for murine brain tumors are superior to those at $1.5 \mathrm{~T}$. In fact, imaging resolution of tumor volume at $7 \mathrm{~T}$ may be in the order of $0.1 \mathrm{~mm}^{3}$. Despite the obvious advantages of a $7 \mathrm{~T}$ magnet system for murine brain imaging, the $1.5 \mathrm{~T}$ system described here has appeal because of its widespread availability to researchers working within or near hospital centers in which clinical MR units are often found.

For the evaluation of tumor size, we found that gadolinium enhancement was superior to noncontrast T1-weighted images. Not only did the tumors display almost immediate enhancement 
following intravenous tail vein injections as compared to a 20 minute lag time with intraperitoneal injections, but the enhancement was much brighter. Although the tumor margins were less discrete than T1-weighted images, the T2-weighted images were also informative, demonstrating associated vasogenic edema. In future experimental imaging studies, other MR sequences including FLAIR, diffusion-weighted, and diffusion tensor-imaging could potentially be utilized to study murine brain tumors. ${ }^{32}$ In addition, MR spectroscopy (MRS) has been performed in mice to study cerebral metabolite profiles in the context of ischemia and stroke. ${ }^{33,34}$ It is possible that MRS will be of value in studying the brain tumors that arise in mice in the same way that MRS has helped with the study of human brain tumors. ${ }^{35,36}$ However, for MRS to be successful in mice, higher field strength magnets in the order of $7-12 \mathrm{~T}$ are required. ${ }^{34}$

Glioblastoma, meningioma and medulloblastoma are three primary brain tumors that are commonly seen in clinical practice and towards which much research is dedicated to develop new treatments. Not only do these tumors differ greatly in biology, but they also have properties which allow for their growth in different intracranial compartments. To our knowledge, this is the first study to describe an imaging technique which was successful in characterizing the presence and growth of brain tumors in the posterior fossa, the supratentorial frontal lobe, and the anterior cranial base. As the incidence of brain tumors in either xenotransplanted or genetically engineered mice is generally not unity, another benefit of noninvasive screening by MR is early detection of tumors in asymptomatic mice, a determination which may prevent the inclusion of nontumor bearing mice into a given study.

Supratentorial intracerebral tumours formed in all mice that were grafted with U87 MG astrocytoma cells. On average, signs of raised intracranial pressure could be detected by day 30 . However, with the use of our MRI protocol, small, asymptomatic tumor growth was visualized on day 19 . These early tumors first appear as homogenously enhancing lesions but as they progress, the periphery remains brightly enhancing with the center becoming hypointense, suggesting necrosis. Interestingly, however, on histopathology the tumors do not demonstrate central necrosis. Rather, there is a paucity of vessels centrally as compared to the periphery of the tumor. In this model, there was a well-defined plane between the tumor and the brain without invasion of the parenchyma. This lack of invasiveness of U87 MG astrocytoma cells highlights one of the major drawbacks of xenografted tumors into nude mice. Hence, the requirement to identify new mouse models in which the histopathological features of the human disease are recapitulated in the mouse.

Murine models attempting to recapitulate intracranial growth of meningiomas in the usual anatomical sites are few and recent. ${ }^{37,38}$ The IOMM-Lee meningioma cell line used in this study invaded the bone readily and extended into and invaded the surrounding soft tissues. Mice xenotransplanted with the IOMMLee cell line generally became symptomatic by 14 days after injection. By way of contrast, mice injected with the F5 meningioma cell line developed tumors that grew preferentially along the convexity with signs of raised increased intracranial pressure occuring 21 days post-injection. The MR imaging features and histopathology of these two cell lines differed. The tumors derived from IOMM-Lee cells had a thin rim of contrast enhancement and a central hypointensity on T1-weighted images, whereas the F5 tumors were homogenously enhancing. Histologically, IOMM-Lee tumors grew in hypercellular sheets without whorl formation and invaded along vessels into the brain parenchyma mimicking a human malignant meningioma. The MIB-1 index was over $30 \%$ with necrosis at the center of the tumors. By histopathology, F5 tumors were more reminiscent of benign meningiomas with some whorl formation, but no evidence of brain, cranial nerve or bone invasion. Necrosis was not seen. Accordingly, the in vivo growth characteristics of IOMM-Lee and F5 cell lines mimic malignant and benign meningiomas, respectively, and may serve as useful models in the future for the evaluation of therapeutics for these tumors.

The posterior fossa tumors in Patched $^{+/}$mice had predominantly rim enhancement after intravenous gadolinium administration, unlike the bright homogeneous enhancement most human medulloblastomas demonstrate. These tumors were generally well-vascularized, suggesting that the lack of tumor vasculature is not a factor in the limited enhancement pattern.

High resolution 1.5 T MRI images of xenografted and genetically modified mouse brain tumor models have been obtained for tumors growing at the skull base, and within intracerebral and intracerebellar locations. The growth of these tumors could be followed with serial imaging of asymptomatic mice. With the increased availability and number of genetically modified mice that develop brain tumors that recapitulate the human disease, the ability to obtain accurate images of tumor size and location will help determine tumor growth without resorting to sacrifice of the animal during treatment. The development and application of novel therapeutic strategies, such as convection enhanced delivery, gene therapy, RNA interference, and immunotoxin therapy, for murine brain tumor models may be assisted by such imaging systems.

\section{ACKNOWLEDGEMENT}

We thank Ian McCutcheon (University of Texas, M.D. Anderson Cancer Center, Houston, Texas) for his assistance with the mouse modeling of xenotransplanted brain tumors.

Sources of Support: Dutch Cancer Society "Koningin Wilhelmina Fonds" (WRvF), MDT and TGM are Terry Fox NCIC Post-MD fellows with funds from the Terry Fox Run. This study was supported in part by grants from the Canadian Institutes of Health Research (CIHR) the Pediatric Brain Tumor Foundation of the United States, and Katie's Kids for the Cure. JTR is a Scientist of the CIHR.

\section{REFERENCES}

1. Holland EC, Celestino J, Dai C, et al. Combined activation of Ras and Akt in neural progenitors induces glioblastoma formation in mice. Nature Genetics 2000;25:55-57.

2. Koutcher JA, Hu X, Xu S, et al. MRI of mouse models for gliomas shows similarities to humans and can be used to identify mice for preclinical trials. Neoplasia 2002;4:480-485.

3. Ding H, Roncari L, Shannon P, et al. Astrocyte-specific expression of activated p21-ras results in malignant astrocytoma formation in a transgenic mouse model of human gliomas. Cancer Res 2001;61:3826-3836

4. Bockhorst K, Els T, Kohno K, Hoehn-Berlage M. Localization of experimental brain tumors in MRI by gadolinium porphyrin. Acta Neurochir Suppl (Wien) 1994;60:347-349.

5. Cortes ML, de Felipe P, Martin V, et al. Successful use of a plant gene in the treatment of cancer in vivo. Gene Ther 1998;5:14991507. 
6. DiMeco F, Rhines LD, Hanes J, et al. Paracrine delivery of IL-12 against intracranial 9L gliosarcoma in rats. J Neurosurg 2000;92:419-427.

7. Gill M, Miller SL, Evans D, et al. Magnetic resonance imaging and spectroscopy of small ring-enhancing lesions using a rat glioma model. Invest Radiol 1994;29:301-306.

8. Kenney J, Schmiedl U, Maravilla K, et al. Measurement of bloodbrain barrier permeability in a tumor model using magnetic resonance imaging with gadolinium-DTPA. Magn Reson Med 1992;27:68-75.

9. Kim B, Chenevert TL, Ross BD. Growth kinetics and treatment response of the intracerebral rat 9L brain tumor model: a quantitative in vivo study using magnetic resonance imaging. Clin Cancer Res 1995;1:643-650.

10. Massicotte EM, Buist R, Del Bigio MR. Altered diffusion and perfusion in hydrocephalic rat brain: a magnetic resonance imaging analysis. J Neurosurg 2000;92:442-447.

11. Remsen LG, McCormick CI, Roman-Goldstein S, et al. MR of carcinoma-specific monoclonal antibody conjugated to monocrystalline iron oxide nanoparticles: the potential for noninvasive diagnosis. AJNR Am J Neuroradiol 1996;17:411-418.

12. Ross BD, Zhao YJ, Neal ER, et al. Contributions of cell kill and posttreatment tumor growth rates to the repopulation of intracerebral 9L tumors after chemotherapy: an MRI study. Proc Natl Acad Sci USA 1998;95:7012-7017.

13. Runge VM, Jacobson S, Wood ML, et al. MR imaging of rat brain glioma: Gd-DTPA versus Gd-DOTA. Radiology 1988;166:835838.

14. Smith DA, Clarke LP, Fiedler JA, et al. Use of a clinical MR scanner for imaging the rat brain. Brain Res Bull 1993;31:115-120.

15. Wilkins DE, Raaphorst GP, Saunders JK, et al. Correlation between Gd-enhanced MR imaging and histopathology in treated and untreated 9L rat brain tumors. Magn Reson Imaging 1995;13:89-96.

16. Wilmes LJ, Hoehn-Berlage M, Els T, et al. In vivo relaxometry of three brain tumors in the rat: effect of Mn-TPPS, a tumorselective contrast agent. J Magn Reson Imaging 1993;3:5-12.

17. Wolf RF, Lam KH, Mooyaart EL, et al. Magnetic resonance imaging using a clinical whole body system: an introduction to a useful technique in small animal experiments. Lab Anim 1992;26:222-227.

18. Blankenberg F, Conley FK, Sayre J, Enzmann D. MR imaging in an experimental model of brain tumor immunotherapy. AJNR Am J Neuroradiol 1991;12:543-548.

19. Randazzo BP, Kesari S, Gesser RM, et al. Treatment of experimental intracranial murine melanoma with a neuroattenuated herpes simplex virus 1 mutant. Virology 1995;211:94-101.

20. Rye PD, Norum L, Olsen DR, et al. Brain metastasis model in athymic nude mice using a novel MUC1-secreting human breastcancer cell line, MA11. Int J Cancer 1996;68:682-687.

21. Cha S, Johnson G, Wadghiri YZ, et al. Dynamic, contrast-enhanced perfusion MRI in mouse gliomas: correlation with histopathology. Magn Reson Med 2003;49:848-855.
22. Benedetti S, Pirola B, Pollo B, et al. Gene therapy of experimental brain tumors using neural progenitor cells. Nat Med 2000;6:447450.

23. Xu S, Gade TPF, Matei C, et al. In vivo multiple-mouse imaging at 1.5 T. Magn Reson Imaging 2003;49:551-557.

24. Goldbrunner RH, Wagner S, Roosen K, Tonn JC. Models for assessment of angiogenesis in gliomas. J Neurooncol 2000;50: 53-62.

25. Rajan SS, Rosa L, Francisco J, et al. MRI characterization of 9Lglioma in rat brain at 4.7 Tesla. Magn Reson Imaging 1990;8: 185-190.

26. Raila FA, Bowles AP Jr, Perkins E, Terrell A. Sequential imaging and volumetric analysis of an intracerebral C6 glioma by means of a clinical MRI system. J Neurooncol 1999;43:11-17.

27. Moore A, Marecos E, Bogdanov A Jr, Weissleder R. Tumoral distribution of long-circulating dextran-coated iron oxide nanoparticles in a rodent model. Radiology 2000;214:568-574.

28. Lee WH. Characterization of a newly established malignant meningioma cell line of the human brain: IOMM-Lee. Neurosurgery 1990;27:389-395; discussion 396.

29. Yazaki T, Manz HJ, Rabkin SD, Martuza RL. Treatment of human malignant meningiomas by G207, a replication-competent multimutated herpes simplex virus 1. Cancer Res 1995;55:47524756.

30. Messier C, Emond S, Ethier K. New techniques in stereotaxic surgery and anesthesia in the mouse. Pharmacol Biochem Behav 1999;63:313-318.

31. Chiang C, Litingtung Y, Lee E, et al. Cyclopia and defective axial patterning in mice lacking Sonic hedgehog gene function. Nature 1996;383:407-413.

32. Zhang J, van Zijl PC, Mori S. Three-dimensional diffusion tensor magnetic resonance microimaging of adult mouse brain and hippocampus. Neuroimage 2002;15:892-901.

33. Schwarcz A, Natt O, Watanabe T, et al. Localized proton MRS of cerebral metabolite profiles in different mouse strains. Magn Reson Med 2003;49:822-827.

34. Hoehn M, Nicolay K, Franke C, van der Sanden B. Application of magnetic resonance to animal models of cerebral ischemia. $\mathrm{J}$ Magn Reson Imaging 2001;14:491-509.

35. Preul MC, Caramanos Z, Collins DL, et al. Accurate, noninvasive diagnosis of human brain tumors by using proton magnetic resonance spectroscopy. Nat Med 1996;2:323-325.

36. Preul MC, Caramanos Z, Villemure JG, et al. Using proton magnetic resonance spectroscopic imaging to predict in vivo the response of recurrent malignant gliomas to tamoxifen chemotherapy. Neurosurgery 2000;46:306-318.

37. McCutcheon IE, Friend KE, Gerdes TM, et al. Intracranial injection of human meningioma cells in athymic mice: an orthotopic model for meningioma growth. J Neurosurg 2000;92:306-314.

38. Kalamarides M, Niwa-Kawakita M, Leblois H, et al. Nf2 gene inactivation in arachnoidal cells is rate-limiting for meningioma development in the mouse. Genes Dev 2002;16:1060-1065. 